\title{
Elogio à crítica: Resenha do livro A Saúde em debate na Educação Física, * organizado por Bagrichevsky, Palma e Estevão
}

Yara Lacerda**

Resumo: O livro Saúde em debate na educação física propõe-se a discutir e refletir sobre a questão da saúde, tendo como pano de fundo o campo da educação física, enriquecido com a contribuição de outros segmentos profissionais que também refletem sobre a saúde. Os principais enfoques abordados são as causas, os riscos, as conceituações e as intervenções que incidem na área. Um dos pontos evidentes na obra é a necessidade de repensar a saúde de uma forma mais aprofundada, criando um distanciamento de análises simplistas.

Palavras-chave: saúde, atividade física, estilo de vida.

As idéias expressas no livro Saúde em debate na Educação Física, como fruto do trabalho de dois anos do GTT I saúde do CBCE, são saudadas com boas vindas e como fonte estimulante de reflexão sobre o panorama da saúde visto sob diversos ângulos.

A publicação do livro é a conseqüência das preocupações que acompanham o grupo de estudo, que além da produção escrita, estabelece e organiza fóruns de debate, nos quais os olhares oriundos de diferentes áreas do conhecimento acadêmico se entrecruzam.

Os vários aspectos que iluminam a discussão enfatizam o axioma atividade física é saúde, por intermédio da recomendação do estilo de vida ativo e/ou via exercício físico. A relação simplista de causa e efeito, que ignora as inúmeras variáveis que interferem e influenciam a temática, é discutida e posta em xeque.

Como a tendência hegemônica manifesta-se às vezes de forma nefasta, o debate estabelecido pelos autores, este sim, para brincarmos um pouco com o conceito de saúde, é saudável para o campo da educação física.

Os organizadores preocuparam-se em reunir visões de profissionais vinculados à área da saúde sem ficarem restritos ao campo

* Livro organizado por Marcos Bagrichevsky, Alexandre Palma e Adriana Estevão. ** Doutora em Educação Física e professora dos cursos de Educação Física das Universidades Gama Filho e Estácio de Sá/RJ.

Movimento, Porto Alegre, v. 11, n. 1, p.183-191, janeiro/abril de 2005 
específico da educação física, fato este que estabelece novas perspectivas sobre o tema. As discussões exclusivamente internas dos campos profissionais correm o risco de transformarem-se em estéreis, circulares e talvez antropofágicas. A formação dos onze autores selecionados percorre outros campos como da ciência social, saúde pública e filosofia.

Além da saúde como área e como temática a ser analisada por estas diferentes formações profissionais, ela é também observada pelos profissionais de educação física que colaboraram com o projeto sob várias óticas, como por exemplo a da promoção e prevenção, a da causalidade, a da educação física escolar e a da relacionada às questões do gênero.

A presença em alguns artigos de autores como Canguilhem (1976, 1990, 1995), na discussão da saúde e da doença, torna a priori o livro respeitável e digno de ser considerado como uma ótima contribuição para os fóruns de debate. Como médico Canguilhem foi um dos marcos para determinar os possíveis caminhos epistemológicos nas discussões acerca da saúde. A descentralização das abordagens do segmento biológico da saúde, que até então tem tendido a monopolizá-la, não deve prescindir da presença desse autor. Outros autores de igual importância foram utilizados para referenciarem os textos, como Lefévre (1991), Restrepo (2001), Morin $(1987,1996)$, Sevcenko (1993), Foucault (1997), entre outros, reforçando o caráter multidisciplinar da obra sobre a temática da saúde na educação física.

Percebe-se uma análise em dois campos: nas conceituações para gerar melhor entendimento do que está sendo discutido e nele podese considerar os artigos I, II, III, IV, VI e IX; e nas intervenções com os artigos V, VII e VIII.

A idéia básica é discutir as nuances em relação aos conceitos, promoções, prevenções, intervenções, riscos e causas que possam influir sobre a discussão da saúde.

As abordagens sobre as causalidades em relação ao binômio exercício e saúde fogem ao consenso, ratificando a proposta de crítica. A força que os estudos científicos (e em alguns casos pretensamente científicos) adquiriram na nossa sociedade é bastante assustadora e também são assustadores os enfoques das causas relacionadas à saúde. Essa força gera alguns problemas entre vários outros: a) a determinação de condutas a partir do resultado dos estudos; b) a superficialidade que às vezes se estabelece nessa correlação de causa e efeito, já que existe um universo probabilístico de causas; c) a ideologia biológica que apresenta-se eliminando outras

Movimento, Porto Alegre, v. 11, n. 1, p.183-191, janeiro/abril de 2005 
análises sobre situações que podem ser enriquecidas se olhadas de outras formas.

Levar em consideração os diferentes tipos de causas e especificidades que as acompanham cria um enfoque de compreensão mais aprofundado, distanciando-nos dos clichês que se apresentam nas discussões sobre a temática exercício/saúde. Já que, sob a influência da força que os resultados dos estudos e pesquisas científicas têm sobre nós, corremos o risco de pautar diversos comportamentos baseados nestes estudos, é necessário dispensar uma grande atenção para a possibilidade de interpretações equivocadas a respeito da correlação estatística de eventos e das análises feitas.

As críticas estendem-se também à forma de confecção das pesquisas. Esse fato não só contribui para uma desmistificação do poder dos resultados, como também para perceber-se a necessidade de cuidados para obter fidedignidade. A respeito da enorme quantidade de artigos sobre atividade física e saúde encontrados no Medline, inúmeros deles com resultados calcados nas correlações estatísticas, Bagrichevsky, Palma e Estevão (2003, p. 42) ponderam oportunamente que

[...] a aceitação acrítica desses achados acaba por não colaborar com o avanço da ciência [...] se as relações estão bem estabelecidas porque elas continuama serestudadas, cada vez mais? Talvez porque não estejam tão bem consolidadas, de fato.

Da mesma forma que Bagrichesky, Palma e Estevão discutem as diferentes possibilidades na relação causa/efeito, Waissmann (2003) discute as diferentes formas de desigualdades que podem vir a lançar novas luzes sobre as relações entre desigualdades, mais comumente utilizadas sob o enfoque de sociais, associadas às implicações com a atividade física/exercício.

Para o autor, o termo "desigualdade social", ao invés de esclarecer, mascara todas as possíveis nuances. Ao ser utilizada essa expressão, além de não se estabelecer um indicador mais preciso, ocultam-se as diferenças como a socioeconômica, renda e trabalho, saúde e condições sanitárias gerais, dificuldades relativas à educação, aspectos étnicos, de cor e biológicos.

Novamente, o não aprofundamento no tema e o tratamento superficial podem gerar discursos levianos que acabam por produzir e conduzir a omissões e radicalismos no pensar e no agir. Percebe-se que para o autor, existe mais uma equalização das diferenças do que um respeito a elas.

Também as questões dos estilos de vida e dos riscos à saúde são discutidas evidenciando as filigranas que as envolvem. Consi-

Movimento, Porto Alegre, v. 11, n. 1, p.183-191, janeiro/abril de 2005 
derando o sentido da ironia fina de Millor Fernandes (CASTIEL, 2003, p. 82), que brincou perguntando "probleminhas terrenos: quem vive mais, morre menos?" Castiel, reflete sobre a tendência atual de exorcizar os fantasmas da morte e do envelhecimento adotando-se, no dito do senso comum, um "estilo de vida sadio". Esse discurso, utilizado inclusive pela mídia, o que contribui para potencializar os efeitos, é recheado de bons alvitres sobre moderação, temperança e afastamento cuidadoso dos riscos que possam influenciar a diminuição da longevidade. Para o autor, é interessante observar que apesar da valorização da vida longa, que naturalmente aumentaria as possibilidades de um quadro compatível com a velhice e portanto menos probabilidades de se aproximar das características da juventude, o jovem, simultânea e paradoxalmente é cada vez mais valorizado. Talvez pudéssemos apontar isso como um dos paradoxos dos tempos atuais. Quero viver mais, mas quero ficar sempre jovem e não quero envelhecer. O cuidado com os ditos "riscos" não parece ser apenas a tentativa de viver bem. Simbolicamente, talvez seja a negação do envelhecimento.

Apesar do senso comum defender, até mesmo em prol dos interesses diversos, às vezes comerciais, o conceito de "risco" como uma idéia única, novamente o autor aprofunda a idéia, tal qual os outros que contribuem para esta obra, da noção multiforme de risco, que pode envolver aspectos econômicos, ambientais, condutas pessoais, dimensões interpessoais, criminais, entre outros. No que se poderia chamar de traçado dos bastidores do surgimento do movimento saúde, englobando a promoção e a prevenção da saúde, Castiel (2003) aponta o campo onde prospera a ênfase dada aos comportamentos ligados ao estilo de vida e aos comportamentos de risco.

A promoção da saúde está em franca expansão, entretanto, campeia uma confusão, e não só a profusão, em relação aos termos e sentidos dados a eles. As idéias aparecem em expressões como "promoção de saúde", "comportamento na proteção à saúde", "comportamento na prevenção à doença", "comportamento na saúde preventiva" e "estilo de vida saudável".

Todos estes termos acabam sendo polissêmicos e ao mesmo tempo que atestam a preocupação vigente, também apontam a carência de análises e esclarecimentos.

A carência de análises e esclarecimentos ainda é apontada em relação ao discurso da saúde na escola, por intermédio das falas de alunos do ensino fundamental, que apresentam-se prisioneiros do sentido linear da atividade física geradora de saúde. Para Devide 
(2003), a ampliação do entendimento que os professores têm da educação física escolar frente à saúde é fundamental para perpetuar ou minimizar a noção de causalidade atividade física/saúde.

Mira (2003, p. 169) inclui também suas preocupações no ensaio referente à relação causa e efeito no binômio exercício físico/saúde, quando afirma que

entre exercício físico e saúde existeminter-relações, interações, retroações complexas e recíprocas, mas não há uma relação positiva de causa e efeito. De maneira geral, é a saúde que conduz à atividade e ao exercício e não ao contrário.

O autor argumenta na sua crítica que a afirmação atestando o elemento exercício físico como fator de saúde e eficaz na prevenção de doenças está muito mais apoiado em critérios de valor do que em resultados obtidos por intermédio de pesquisas científicas.

A idéia de valor perpassando as questões da saúde é analisada por Caponi (2003) no texto “A saúde como objeto de reflexão filosófica", identificando a necessidade da reflexão filosófica em relação ao conceito "saúde". A autora parte da tentativa de compreender o conceito de saúde na ótica de Canguilhem (1990), comparando-o com outros autores como Boorse (1975) e Dagonet (1996), entre outros. Justifica a discussão das questões relativas à saúde no âmbito filosófico, alegando ser esse tema freqüente na época clássica e recebendo também a contribuição de filósofos do porte de Kant, Leibniz, Diderot, Descartes e posteriormente, Nietzsche. O conceito de saúde com base apenas nos índices quantitativos de médias estatísticas, que apontam as normalidades dos seres humanos sem considerarem as individualidades, é comentado por esta autora, apoiando-se principalmente no referencial teórico de Canguilhem. Para Caponi (p. 121),

Quando falamos de saúde não podemos evitar as referências à dor ou ao prazer e, desse modo, estamos introduzindo, sutilmente, algo que escapa às medições, algo que Canguilhem chamou de "corpo subjetivo". Se consideramos este elemento, não poderemos deixar de falar na primeira pessoa, ali onde o discurso médico teima em falar na terceira pessoa.

É levantada a hipótese, ainda a partir de Canguilhem, que a saúde deve ser encarada, além da possibilidade de ficar doente, como a capacidade de recuperação, já que a fragilidade e a enfermidade são características inerentes à nossa condição de seres vivos. Além dos aspectos pessoais, merecem obrigatoriamente atenção as condições impostas pelo meio tais como alimentação deficiente, escolaridade precária, condições sanitárias deficientes, que constituem um conjunto de elementos que não pode ser 
abandonado nos planejamentos de políticas públicas e intervenções. Apesar de considerar o ambiente intervindo no estado de saúde, a autora identifica limites nesses aspectos e registra a crítica freqüente em relação ao conceito de saúde emitido pela Organização Mundial de Saúde (OMS): "A saúde é um completo estado de bem-estar físi-co, mental e social e não a mera ausência de moléstia ou doença", que pressupõe esse ambiente quando faz referência ao âmbito social. A utopia do conceito é apontada por ser o estado proposto difi-cilmente atingido na sua totalidade e também por ser impossível medir-se o grau de saúde de uma população dessa forma, considerando-se que as pessoas não mantêm constantemente o estado de bem-estar. O conceito de bem-estar é muito subjetivo levando à necessidade da definição apresentar aspectos mais objetivos. Entretanto, o caráter subjetivo não se separa do conceito de saúde e apesar disso a autora não aponta essa razão como a maior dificuldade do conceito, mas sim os efeitos que pode desencadear no estabelecimento de estratégias políticas de controle do que é considerado fora do normal. A preocupação maior, finalmente apontada, é relativa à idéia do ser humano incluir nas suas experiências de vida a doença, não sendo possível portanto uma saúde idealizada como perfeita. Sendo esse ideal justamente uma das expectativas das políticas públicas, o fato remete a uma ilegitimidade da tentativa de alcançar objetivos impossíveis.

Diferentes preocupações são introduzidas por outros textos do livro, atestando a incontestável multidisciplinaridade oferecida pela obra. Percebe-se uma sofisticação de enfoques quando Oliveira (2003) aborda o que se imagina como o avesso da qualidade de vida, falando da população carcerária. Contrariamente à expectativa de qualidade nesse contexto, a autora aponta um curioso e talvez desconhecido cenário de preocupações com os corpos aprisionados, mostrando a existência de uma indústria que se esconde sob a fachada da segurança. Para ela, "a defesa da qualidade de vida assume conotação correlata à defesa da sociedade" (p. 99), manifestando-se nos mais variados discursos. Evidencia, a partir de análise de autores frente ao problema de segurança, teorias sobre o crime e táticas de controle em diferentes lugares do mundo, relações considerando não apenas os corpos encarcerados, mas as ligações entre a qualidade de vida dos cidadãos, a política de tolerância zero ao descontrole social e os desdobramentos dessa temática.

Como parte das questões contemporâneas é abordado o papel social da mulher frente aos novos tempos e costumes. Mourão e Duarte (2003) propõem uma reflexão sobre as relações entre gênero, trabalho e saúde. As autoras apontam as dificuldades do desdo-

Movimento, Porto Alegre, v. 11, n. 1, p.183-191, janeiro/abril de 2005 
bramento de exigências e tarefas das mulheres gerando graves repercussões, com direito a patologias específicas oriundas dessas novas responsabilidades, como por exemplo, a síndrome da mulher com pressa. Segundo o texto,

esta nova síndrome, segundo especialistas americanos, atinge uma em cada quatro mulheres entre 25 e 55 anos, é uma nova forma branda de depressão, podendo prejudicar a saúde das mulheres e dos homens. Os principais sintomas são ganhode peso, vida sexual desacelerada, desânimo e fadiga (p. 152).

Tendo como dado o depoimento de uma professora universitária, o capítulo passeia sobre a realidade social vigente e identifica as tensões existentes entre as esferas públicas, privadas e as respectivas influências sobre a discussão da temática saúde, considerando as especificidades do universo feminino.

Todos os artigos passam pelo filtro crítico de repensar as afirmações mais comuns e presentes no campo da atividade física e saúde. Enfatizam a derrubada dos slogans que podem vir a se perpetuar nefastamente, caso não sejam analisados e discutidos. A capa do livro retrata a figura de uma Barbie quebrada. Essa boneca é reconhecidamente encarada como símbolo do imaginário de corpo ideal, e por que não, seguindo o ideário de perfeição, de saúde ideal. Lançando mão dessa imagem e suscitando a contramão do modelo perfeito, o livro reforça a intenção de contribuir e promover a discussão proposta.

A leitura de $A$ saúde em debate na educação física insere-se na categoria de leitura obrigatória por aqueles que pretendem repensar, discutir ou criticar as abordagens referentes a esta temática. É muito promissor perceber-se que a educação física como campo profissional, afastando-se cada vez mais de uma fase ingênua e acrítica, adentra mais profundamente num momento onde a crítica e a preocupação com os posicionamentos diante das questões que atravessam os nossos cotidianos de trabalho, delineiam-se com mais clareza.

Movimento, Porto Alegre, v. 11, n. 1, p.183-191, janeiro/abril de 2005 


\section{A praise to critique}

Abstract: The purpose of the book entitled "Discussing health in the field of physical education" is to raise a discussion about health in the field of physical education taking into account the contribution of other professional segments that also think about health. Matters such as cause, risks, concepts and interventions are widely discussed. Furthermore, a crucial contribution of the present book is to explicit the need to think of health in a deeper way avoiding simplistic approaches.

Keywords: Health, physical activity, way of life.

Elogio a la crítica
Resumen: El libro "Salud en debate en la educación fisica"
discute la cuestión de la salud teniendo como pano de
fondo el campo de la educación física, enriquecido con la
contribuición de otros segmentos professio-nales que
tambiém reflexionam sobre el tema. Los principales enfo-
ques abordados son sobre causas, riezgos, conceptua-
ciones y intervenciones. Un punto evidente de la obra es la
necesidade de repensar la salud de una forma más profon-
da, criando distanciamientos de las análisis simplistas.
Palavras-claves: Salud, atividade física, estilo de vida.

\section{Referências}

BAGRICHEVSKY, M.; PALMA, A.; ESTEVÃO, A. (Orgs.). A saúde em debate na educação física. Blumenau: Edibes, 2003, 191p.

Considerações teóricas acerca das questões relacionadas à promoção da saúde. In: BAGRICHEVSKY, M.; PALMA, A.; ESTEVÃO, A. (Orgs.). A saúde em debate na educação física. Blumenau: Edibes, 2003, p.15-32.

Análise sobre os limites da interferência causal no contexto investigativo sobre "exercício físico e saúde". In: BAGRICHEVSKY, M.; PALMA, A.; ESTEVÃO, A. (Orgs.). A saúde em debate na educação física. Blumenau: Edibes, 2003, p33-52.

CAPONI, S. A saúde como objeto de reflexão filosófica. In: BAGRICHEVSKY, M.; PALMA, A.; ESTEVÃO, A. (Orgs.). A saúde em debate na educação física. Blumenau: Edibes, 2003, p.115-136.

CASTIEL, L. D. Quem vive mais morre menos? Estilo de riscos e promoção de saúde. In: BAGRICHEVSKY, M.; PALMA, A.; ESTEVÃO, A. (Orgs.). A saúde em debate na educação física. Blumenau: Edibes, 2003, p.79-98.

Movimento, Porto Alegre, v. 11, n. 1, p.183-191, janeiro/abril de 2005 
DEVIDE, F. A educação física escolar como via de educação para a saúde. In: BAGRICHEVSKY, M.; PALMA, A.; ESTEVÃO, A. (Orgs.). A saúde em debate na educação física. Blumenau: Edibes, 2003, p.137-150.

MIRA, C. M. Exercício físico e saúde: da crítica prudente. In: BAGRICHEVSKY M.; PALMA, A.; ESTEVÃO, A. (Orgs.). A saúde em debate na educação física. Blumenau: Edibes, 2003, p.169-191.

MOURÃO, L.; DUARTE, C. Eqüidade de gênero e saúde: desafio dos novos tempos sociais, In: BAGRICHEVSKY, M.; PALMA, A.; ESTEVAO, A. (Orgs.). A saúde em debate na educação física. Blumenau: Edibes, 2003, p.151-168.

OLIVEIRA, S. Qualidade de vida, corpos aprisionados. In: BAGRICHEVSKY, M.; PALMA, A.; ESTEVÃO, A. (Orgs.). A saúde em debate na educação física. Blumenau: Edibes, 2003, p.99-114.

WAISSMANN, W. Desigualdade social e atividade física. In: BAGRICHEVSKY M.; PALMA, A.; ESTEVÃO, A. (Orgs.). A saúde em debate na educação física. Blumenau: Edibes, 2003, p.53-78. 